\title{
Characterization of a novel cellular defect in patients with phenotypic homozygous familial hypercholesterolemia
}

\author{
Dennis Norman, Xi-Ming Sun, Mafalda Bourbon, Brian L. Knight, \\ Rossitza P. Naoumova, and Anne K. Soutar \\ Lipoprotein Group, MRC Clinical Sciences Centre, Imperial College School of Medicine, Hammersmith Hospital, \\ London W12 ONN, United Kingdom \\ Address correspondence to: Anne K. Soutar, Lipoprotein Group, MRC Clinical Sciences Centre, \\ Imperial College School of Medicine, Hammersmith Hospital, London W12 ONN, United Kingdom. \\ Phone: 0181-383-3262/2324; Fax: 0181-383-2077; E-mail: a.soutar@rpms.ac.uk. \\ Received for publication March 1, 1999, and accepted in revised form July 16, 1999.
}

Familial hypercholesterolemia $(\mathrm{FH})$ is characterized by a raised concentration of LDL in plasma that results in a significantly increased risk of premature atherosclerosis. In FH, impaired removal of LDL from the circulation results from inherited mutations in the LDL receptor gene or, more rarely, in the gene for apo B, the ligand for the LDL receptor. We have identified two unrelated clinically homozygous FH patients whose cells exhibit no measurable degradation of LDL in culture. Extensive analysis of DNA and mRNA revealed no defect in the LDL receptor, and alleles of the LDL receptor or apo B genes do not cosegregate with hypercholesterolemia in these families. FACS ${ }^{\circledR}$ analysis of binding and uptake of fluorescent LDL or anti-LDL receptor antibodies showed that LDL receptors are on the cell surface and bind LDL normally, but fail to be internalized, suggesting that some component of endocytosis through clathrin-coated pits is defective. Internalization of the transferrin receptor occurs normally, suggesting that the defective gene product may interact specifically with the LDL receptor internalization signal. Identification of the defective gene will aid genetic diagnosis of other hypercholesterolemic patients and elucidate the mechanism by which LDL receptors are internalized.

J. Clin. Invest. 104:619-628 (1999).

\section{Introduction}

Familial hypercholesterolemia (FH) occurs with a frequency of approximately 1 in 500 in most populations and is, therefore, one of the most commonly inherited disorders of metabolism. Heterozygous FH results from impaired removal of LDL from the circulation, usually because of defective LDL receptor function caused by mutations in this gene. A similar, but generally milder, phenotype also occurs in patients with a defect in the gene for apo $\mathrm{B}$, a specific ligand for the LDL receptor. The approximately 2 -fold increase in the concentration of LDL in the circulation in heterozygous FH patients results in an increased risk of coronary heart disease (CHD), although there is a wide variation in the severity of disorder and in the response to lipid-lowering therapy. The disease is inherited as a dominant trait with a gene dosage effect, in that homozygous FH patients have a greater than 5-fold increase in plasma LDL concentration. Aortic root disease is the most common cardiac manifestation; by puberty, all patients have atheromatous involvement of the ascending aorta, resulting in ostial stenosis with a potentially fatal outcome, unless they are treated rigorously (1).

Much recent research has been directed toward determining the underlying cause of the variability in the severity of the heterozygous FH phenotype, both in terms of plasma LDL cholesterol concentration and susceptibility to premature atherosclerosis. Thus, we and others have characterized the underlying mutation in the LDL receptor gene of numerous $\mathrm{FH}$ patients so that groups with the same or different genotype could be compared (2-4). Identification of the underlying genetic defect is also an important aid to early identification of affected relatives in a family so that effective preventative measures can be taken. However, even after detailed analysis of the LDL receptor gene, several studies reported that no underlying defect could be found in about $15 \%$ of patients with a diagnosis of heterozygous $\mathrm{FH}(3,5)$.

The possibility that a hitherto unknown genetic defect could cause the typical FH phenotype was reinforced when we were unable to detect a genetic defect in the LDL receptor gene in two unrelated patients with a clinical diagnosis of homozygous $\mathrm{FH}$, even though their cells in culture degraded negligible amounts of LDL. In this paper we report that the cellular defect in cells from these two patients does not lie in the LDL receptor protein itself, but in some aspect of its trafficking in the cell.

\section{Methods}

Subjects. FH-1, the first of the two index patients in this study, attends the Hammersmith Hospital Lipid Clinic. She has a long-standing presumptive diagnosis of homozygous FH based on a raised plasma cholesterol concentration, the presence of extensive cutaneous 

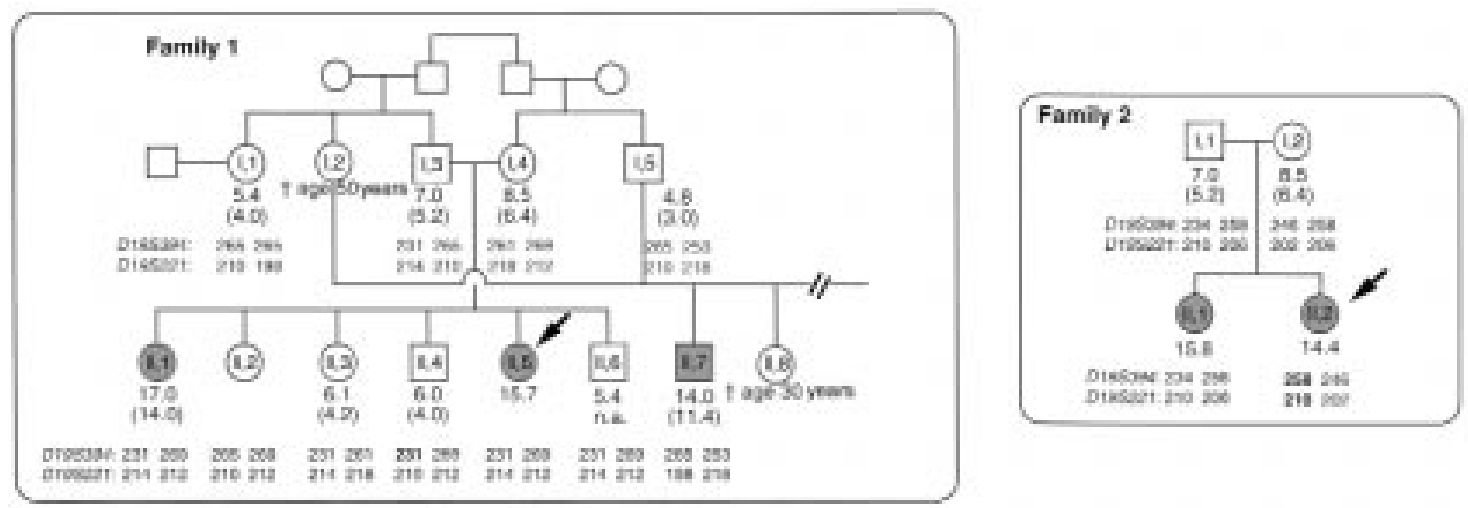

\section{Figure 1}

Pedigrees of the index patients. The filled symbols indicate individuals with a clinical diagnosis of possible homozygous $\mathrm{FH}$ in each family, with an arrow indicating the 2 index patients. Plasma cholesterol values (in $\mathrm{mmol} / \mathrm{L}$ ) are shown below each symbol, with LDL cholesterol values (where available) in brackets beneath. Note that the cholesterol concentration in the index patient in family 1 was measured during treatment with cholestyramine, while the others are all pretreatment values. The sizes of the PCR products (bp) of alleles of 2 markers (D19S394 and D19S221) that flank the LDL receptor gene locus are shown below the plasma cholesterol values. One recombination event is indicated in bold. †Deceased.

xanthomata in the webs of her fingers and creases of her hands, and tendon xanthomata from a young age, as well as supravalvular aortic stenosis and premature CHD. The clinical characteristics of this patient, who is of Turkish origin, have been described in detail elsewhere (6). No pretreatment plasma cholesterol values are known for this patient, but when she was referred to the Hammersmith Hospital on treatment with simvastatin $(20 \mathrm{mg} / \mathrm{d})$ and cholestyramine $(14 \mathrm{~g} / \mathrm{d})$, her plasma lipids were as follows: total cholesterol, 14.9 $\mathrm{mmol} / \mathrm{L}$; triglyceride, $0.98 \mathrm{mmol} / \mathrm{L}$; HDL cholesterol, $0.88 \mathrm{mmol} / \mathrm{L}$; LDL cholesterol, $13.6 \mathrm{mmol} / \mathrm{L}$. Samples from the second patient and her family were sent to us by David Worthington (Birmingham Children's Hospital, Birmingham, United Kingdom) for analysis of LDL receptor function to confirm a clinical diagnosis of possible homozygous FH. The index patient in family 2, who is of Asian Indian origin, had a plasma cholesterol concentration of $14.4 \mathrm{mmol} / \mathrm{L}$ at 9 years of age and has a sibling whose plasma cholesterol was 15.8 $\mathrm{mmol} / \mathrm{L}$ at 7 years of age.

Blood samples were obtained from the index patients and their relatives for isolation of DNA and for preparation of Epstein-Barr virus-transformed (EBV-transformed) lymphoblast cell lines, as described previously (7).

Analysis of the LDL receptor gene. Using phenol-chloroform extraction of cell extracts, as described previously $(7,8)$, total cellular mRNA was isolated from EBV-transformed lymphoblasts that had been preincubated for $18-20$ hours in medium containing lipoprotein-deficient serum $(10 \% \mathrm{vol} / \mathrm{vol})$ and compactin $(1.08 \mu \mathrm{g} / \mathrm{mL})$.

Overlapping fragments of the LDL receptor cDNA were amplified by nested RT-PCR. The RT reaction contained $1-2 \mu \mathrm{g}$ of mRNA in a total volume of $20 \mu \mathrm{L}$ of $1 \times$ buffer (Roche Diagnostics Ltd.., Lewes, East Sussex, United Kingdom) containing 200 ng of specific primer (5'-ATGGA ATGTG GTAGG GGTCG GGTGG ATGGG), random primers $\left[1 \mathrm{OD}_{260} \mathrm{U} \mathrm{pd}(\mathrm{N}) 6\right]$, RNase inhibitor (40 U), avian myeloblastoma virus reverse transcriptase ( $40 \mathrm{U}$ ), $5 \mathrm{mM}$ DTT, and $0.625 \mathrm{mM}$ of each dNTP, and was incubated for 45 minutes at $42^{\circ} \mathrm{C}$, followed by 3 minutes at $95^{\circ} \mathrm{C}$. Three first-round products were amplified and nested with primers as follows: product 1 (exons 1-8) first-round primers 166 (5'-ACACT GCCTG GCAGA GGCTG C) and 227 (5'-GCGAC CACGT TCCTC AGGTT GGGGA TGAGG), nested with primers 220 (5'-CGAGT TCCAG TGCCA AGACG GGAAA TGCAT C) and 225 (5'-TGTGC CACCC TCCAG GTTCA CGCAG AGCTG); product 2 (exons 6-14) first-round primers 169 (5'-CACGA TGGGA AGTGC ATCTC TC) and 233 (5'-GCTGA CCTTT AGCCT GACGG TGGAT G), nested with primers 224 (5'-GGACC CAACA AGTTC AAGTG TCACA GCGGC G) and 231 (5'-TGCTC AGGGT GGTCCT CTCAC ACCAG TT); product 3 (exons 13-18) first-round primers 230 (5'-CCGCC TGTAC TGGGT TGACT CCAAA CTTCA) and 183 (5'-GCAGG GGCGG GACTC CAGGCA), nested with primers 184 (5'-AAACC TTACT GTCCC CAGAG GATAT AG) and 183 (as above).

The second-round PCR products were digested with exonuclease I ( $20 \mathrm{U})$ and shrimp alkaline phosphatase (4 $\mathrm{U}$ ) for 15 minutes at $37^{\circ} \mathrm{C}$, and the enzymes were heat-inactivated by incubation at $85^{\circ} \mathrm{C}$ for 15 minutes (Sequenase PCR Product Sequencing Kit; Amersham International, Amersham, United Kingdom) and subjected to automated nucleotide sequencing on an ABI 373 DNA sequencer (PE Applied Biosystems, Warrington, Chesire, United Kingdom). Product 1 was sequenced with primers 54 (5'-CCCCA GCTGT GGGCC TGCGA CAA) and 55 (5'-CCATC CGAGC CATCT TCGCA GTC); product 2 was sequenced with primers F (5'-GCACA GTAGA TTCTA TTGCT G), G 
(5'-CCTGA GGAAC GTGGT CGCTCT), and 77B (5'CTACT CGCCG GTGAC TG); and product 3 was sequenced with primers $\mathrm{J}$ (5'-GAGGT GTCGG GAACA GGCCG G) and 183 (5'-GCAGG GGCGG GACTC CAGGC A). Sequences were always compared with other, similar samples sequenced on the same run, using the Sequence Navigator program (ABI).

DNA was isolated from whole blood or from cultured lymphoblasts by standard techniques, and Southern blotting or restriction enzyme digestion and sequencing of amplified fragments of the LDL receptor gene was carried out as described previously $(9,10)$.

Genomic DNA was analyzed for the presence of known mutations in the gene for apo B by PCR and digestion of the product as described previously (3).

Linkage analysis. Genotyping of microsatellite markers D19S394 ( 250 kb telomeric of the LDL receptor gene) and D19S221 ( $1.3 \mathrm{Mb}$ centromeric of the gene) was carried out by GeneScan analysis on an ABI 377 automated sequencer, essentially as described by Day and colleagues (11), but with the following primer pairs: for D19S221, 5'-NED-TTATT TCCCG ATTCC TGGCAG and 5'-ATGTC ACCCA GTCTC CAGAT GCAG; for D19S394, 5'-FAM-TCGAG ACTAC AGTGA GCTGT GGTC and 5'-GTGTT CCTAA CTACC AGGCA CAATC. The conditions for PCR were as follows: 1 cycle of 8 minutes at $50^{\circ} \mathrm{C}, 5$ minutes at $94^{\circ} \mathrm{C} ; 5$ cycles of 50 seconds at $94^{\circ} \mathrm{C}, 2$ minutes at $54^{\circ} \mathrm{C}, 2$ minutes at $72^{\circ} \mathrm{C} ; 20$ cycles of 50 seconds at $94^{\circ} \mathrm{C}, 1$ minute at $56^{\circ} \mathrm{C}, 2$ minutes at $72^{\circ} \mathrm{C}$, followed by 1 cycle of $30 \mathrm{~min}-$ utes at $35^{\circ} \mathrm{C}$. The microsatellite marker D2S131, which is closely linked to the gene for apo $\mathrm{B}$, was amplified as above, with primers as follows: 5'-HEX-CAATT GTACC
CCATT TACTG C and $5^{\prime}$-GGGTC CAAGG AACTC TCC. The microsatellite data were analyzed using the Genotyper program (ABI).

Determination of cellular $L D L$ receptor protein content and function. Immunoblotting of LDL receptor protein in cell extracts, and measurement of the uptake and degradation of ${ }^{125}$ I-labeled LDL and ${ }^{125}$ I-labeled $\beta$ VLDL by lymphoblasts in culture, was performed as described previously (3). Semiquantitative immunoblotting of cell extracts after treatment of cells with pronase was carried out as described previously (12).

For FACS analysis of binding of LDL, lymphoblasts were preincubated for 16-18 hours with lipoproteindeficient serum (10\% vol/vol) and compactin (1.08 $\mu \mathrm{g} / \mathrm{mL}$ ), or with lipoprotein-deficient medium containing sterols $(30 \mu \mathrm{g} / \mathrm{mL}$ of cholesterol and $6 \mu \mathrm{g} / \mathrm{mL}$ of 25 hydroxycholesterol) as described previously (3). The lymphoblasts were then washed twice with Puck's saline containing $0.5 \mathrm{mM} \mathrm{CaCl} 2$ and $0.5 \%(\mathrm{wt} / \mathrm{vol}$ ) of BSA (buffer A) and resuspended in the same buffer. Cells $\left(10^{6}\right.$ cells $/ 0.1 \mathrm{~mL}$ of buffer A) were incubated at $4^{\circ} \mathrm{C}$ in $96-$ well, U-shaped rigid plastic plates (Bibby Sterilin Ltd., Stone, Staffordshire, United Kingdom) for 30 minutes with BODIPY-FL LDL complex $(20 \mu \mathrm{g}$ of LDL protein/mL; Molecular Probes Inc., Eugene, Oregon, USA) in the presence or absence of an excess $(1 \mathrm{mg} / \mathrm{mL})$ of unlabeled human LDL. Cells were then washed twice with buffer $\mathrm{A}$ at $4^{\circ} \mathrm{C}$, once with buffer $\mathrm{A}$ without BSA (buffer $B$ ), and then fixed by resuspension in buffer $B$ containing $2 \%(\mathrm{wt} / \mathrm{vol})$ freshly prepared paraformaldehyde. For the analysis of the internalization of LDL receptor protein, cells were incubated with chicken polyclonal anti-human LDL receptor antibody (diluted 1:100

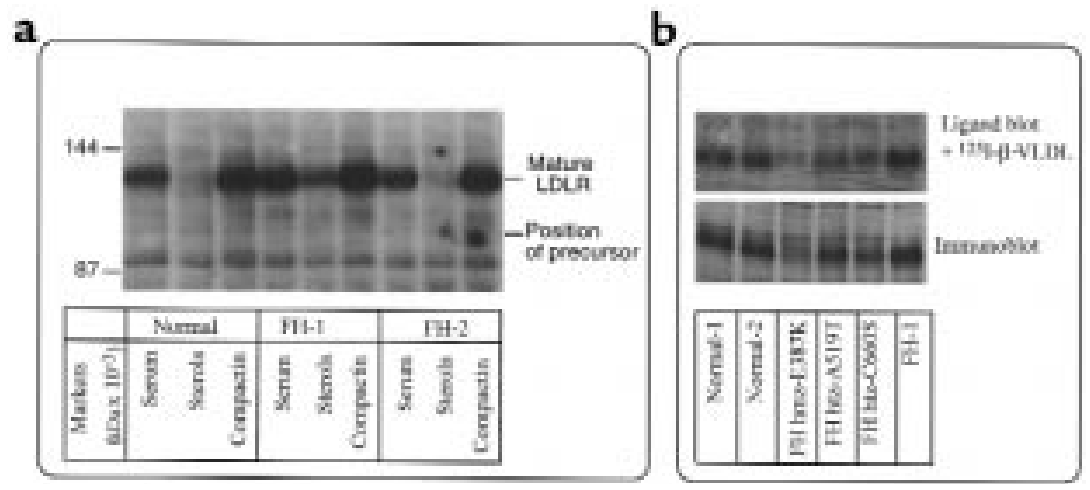

\section{Figure 2}

Detection of LDL receptor protein in cultured lymphoblasts by immunoblotting and ligand blotting. (a) Cells from a normolipemic individual (Normal), the index patient in family $1(\mathrm{FH}-1)$, and the index patient in family $2(\mathrm{FH}-2)$ were incubated for 16 hours in medium containing 10\% (vol/vol) FCS (Serum), 10\% (vol/vol) lipoprotein-deficient serum containing compactin (Compactin), or 10\% (vol/vol) lipoprotein-deficient serum containing cholesterol and 25-hydroxycholesterol (Sterols). Cell extracts were fractionated on nonreduced SDS-PAGE ( $50 \mu \mathrm{g}$ of cell protein/lane) and transferred to nitrocellulose membranes. The membrane was incubated with an anti-LDL receptor mAb ( $\mathrm{mAb} 4 \mathrm{~B} 3$ ), followed by a peroxidase-conjugated anti-mouse IgG; bound antibody was detected by chemiluminescence with 60-second exposure to film. The positions of molecular weight markers are shown on the left, and positions of the mature LDL receptor protein and the expected position of the precursor protein (not visible in these cells) are shown on the right. (b) Cells from a normolipemic control, FH1, a homozygous FH patient with a known mutation in the LDL receptor gene (FH hmz-E387K; ref. 34), and heterozygous FH patients with known mutations in the LDL receptor gene (FH htz-C660S and FH htz-A519T; ref. 3) were preincubated with lipoprotein-deficient serum and compactin and analyzed by ligand blotting with ${ }^{125}$-labeled $\beta$-VLDL (specific activity $=500 \mathrm{dpm} / \mathrm{ng}$ of protein, $1 \mu \mathrm{g}$ of protein/mL; top) or by immunoblotting with $\mathrm{mAb} 4 \mathrm{~B} 3$, as described above (bottom). 
Table 1

Serum lipid levels in family $1^{\mathrm{A}}$

\begin{tabular}{|c|c|c|c|c|c|c|c|}
\hline \multirow[t]{2}{*}{ Subject ${ }^{B}$} & \multirow[t]{2}{*}{ Sex } & \multirow[t]{2}{*}{ Age (years) } & \multirow[t]{2}{*}{ Clinical signs } & \multicolumn{4}{|c|}{ Serum lipids (mmol/L) } \\
\hline & & & & Total cholesterol & HDL cholesterol & Triglycerides & LDL cholestero \\
\hline ।,1 & $\mathrm{F}$ & 59 & - & 5.4 & 0.94 & 0.92 & 4.0 \\
\hline 1,3 & M & 66 & - & 7.0 & NA & NA & 5.2 \\
\hline ।,4 & $\mathrm{F}$ & 66 & - & 8.5 & NA & NA & 6.4 \\
\hline ।,5 & M & 75 & - & 4.8 & 1.31 & 1.16 & 3.0 \\
\hline $\mathrm{II}, 1$ & $\mathrm{~F}$ & 41 & $\mathrm{TdX}^{+}, \mathrm{CAD}^{-}$ & 17.0 & NA & NA & 14.0 \\
\hline 11,2 & $\mathrm{~F}$ & 39 & - & $N A^{C}$ & NA & NA & NA \\
\hline 11,3 & $\mathrm{~F}$ & 35 & - & 6.1 & 1.50 & 0.96 & 4.2 \\
\hline 11,4 & M & 32 & - & 6.0 & 1.30 & 1.48 & 4.0 \\
\hline 11,5 & $\mathrm{~F}$ & 30 & $\mathrm{TdX}^{+}, \mathrm{CAD}^{+}$ & $15.4^{\mathrm{D}}$ & NA & 2.6 & NA \\
\hline 11,6 & M & 27 & - & $N A^{C}$ & NA & NA & NA \\
\hline 11,7 & M & 31 & $\mathrm{TdX}^{+}, \mathrm{CAD}^{-}$ & 14.0 & 0.66 & 4.20 & 11.4 \\
\hline
\end{tabular}

ATotal cholesterol values are only available for family 2, as shown in Figure 1. BNumbered as in pedigree shown in Figure 1. CReported to be normocholesterolemic. ${ }^{1994}$ values during treatment with Questran; no untreated values available. TdX, tendon xanthomata; CAD, coronary artery disease .

in buffer A; Progen Biotechnik GmbH, Heidelberg, Germany) at $4^{\circ} \mathrm{C}$ for 30 minutes, washed 3 times with buffer $\mathrm{A}$, and then incubated for 30 minutes at $37^{\circ} \mathrm{C}$ in the presence or absence of $2 \mathrm{mM} N$-ethyl maleimide (NEM). After incubation, the cells were chilled to $4^{\circ} \mathrm{C}$, washed twice with buffer $\mathrm{A}$, and then incubated with Alexa-488 goat anti-chicken $\operatorname{IgG}(\mathrm{H}+\mathrm{L})$ conjugate (diluted 1:200 in buffer A; Molecular Probes Inc.) for 15 minutes at $4^{\circ} \mathrm{C}$. Cells were washed once with buffer $B$ and resuspended in buffer B containing $2 \%$ paraformaldehyde. Labeled cells were stored in the dark at $4{ }^{\circ} \mathrm{C}$ for not more than 18 hours before FACS analysis.

FACS analysis was carried out with a Becton Dickinson FACS Vantage flow cytometer fitted with an OmniChrome argon laser (Becton Dickinson, Cowley, Oxford, United Kingdom). For cells labeled with BODIPY or ALexa488, the excitation wavelength was $488 \mathrm{~nm}$, and data were collected in FL-1 with a 530$\mathrm{nm}$ band-pass filter. For each analysis, 50,000 events were recorded; the data were gated on the main population identified on the forward scatter $(\mathrm{FSCH})$ and side scatter (SSCH) dot plot (80-85\% of total events), and analyzed with CellQuest software (Becton Dickinson, Chino, California, USA).

Determination of internalization of transferrin. Human transferrin $(100 \mu \mathrm{g}$ in $50 \mu \mathrm{L}$ of PBS; Sigma Chemical Co., St. Louis, Missouri, USA) was labeled with $0.5 \mathrm{mCi}$ of ${ }^{125} \mathrm{I}$ by incubation with Iodogen (Pierce Chemical Co., Rockford, Illinois, USA), essentially as described previously for labeling of mAb's (13). Binding and uptake of ${ }^{125}$ I-labeled transferrin was measured by methods based on those of Buchegger and colleagues $(14,15)$. Lymphoblasts were washed and resuspended in RPMI-1640 medium without serum at $5 \times 10^{6}$ cells $/ \mathrm{mL}$; incubated with ${ }^{125} \mathrm{I}$-labeled transferrin $(0.2$ $\mu \mathrm{g} / \mathrm{mL}$ ) for 30 minutes at $4^{\circ} \mathrm{C}$; washed 3 times with icecold PBS; resuspended in medium containing unlabeled transferrin $(10 \mathrm{mg} / \mathrm{mL})$; and then incubated at $37^{\circ} \mathrm{C}$ for $0-30$ minutes. At each time point, $5 \times 10^{6}$ cells in triplicate were chilled to $4^{\circ} \mathrm{C}$. The medium was removed, and the cells were washed twice with $0.5 \mathrm{~mL}$ $0.2 \mathrm{M}$ acetic acid, $0.5 \mathrm{M} \mathrm{NaCl}(\mathrm{pH} 2.4$ ) to remove surface-bound transferrin and then were solubilized in 1 $\mathrm{mL}$ of $1 \mathrm{M} \mathrm{NaOH}$. The amounts of radioactivity in the medium (secreted transferrin), pooled acid washes (surface-bound transferrin), and solubilized cells (internalized transferrin) were determined with a 1282 CompuGamma Universal Gamma Counter (LKB Wallac; EG\&G Wallac, Milton Keynes, United Kingdom) and expressed per milligram of cell protein assayed in the $\mathrm{NaOH}$ solubilized extract using the protein assay DC kit (Bio-Rad Laboratories Inc., Hercules, California, USA).

\section{Results}

Patients. The pedigrees of the two index patients are shown in Figure 1. The index patient in family 1 (II,5), also referred to below as FH-1, had all the clinical signs of homozygous $\mathrm{FH}$, including a severely raised plasma cholesterol level, extensive cutaneous and tendon xanthomata, supravalvular aortic stenosis, and premature CHD. However, her parents did not have the hypercholesterolemia typical of heterozygous $\mathrm{FH}$, although their values lay above the 90th percentile for their age and gender. The patient has one hypercholesterolemic sibling, who is reported to have tendon xanthomata (II,1) but no signs of CHD. The other siblings in the family were apparently unaffected, although, again, the plasma LDL cholesterol concentration in some of them was above the 90th percentile for their age and gender (II,3 and II,4). There is a severely hypercholesterolemic relative (II,7), who is the first cousin of the two siblings in family 1; he also has planar xanthomata in the webs of his fingers and tendon xanthomas. The parents (I,3 and I,4) of the index patient in family 1 are first cousins, as were the parents (I,2 and I,5) of the third affected member of the family. The affected cousins are closely related, because the father $(\mathrm{I}, 5)$ of this third affected individual (II,7) is also the brother of the mother $(\mathrm{I}, 4)$ of the index patient, and his moth- 
er $(I, 4)$, who died suddenly at the age of 50 years from a possible stroke, was the sister of the father $(I, 3)$ of the index patient. A sibling $(\mathrm{II}, 8)$ of this third affected member of the family also died suddenly at the age of 30 years. Subject II, 7 also has 5 additional living brothers who we have not yet been able to examine. The spouse of the index patient's father's sister $(\mathrm{I}, 1)$ was not known to be related to the family, and this branch of the family was not studied further. Details of the lipid values in family 1 are shown in Table 1.

The index patient in family 2 (II,2; also referred to below as FH-2) and her sibling (II,1) in family 2 were both severely hypercholesterolemic at an early age and were given a diagnosis of possible homozygous FH, although again the plasma cholesterol concentrations of the parents, particularly the mother, were not typi$\mathrm{cal}$ for heterozygous $\mathrm{FH}$. The parents in family 2 were also reported to be first cousins, but no additional members of this family were available for study.

Analysis of the LDL receptor gene and $m R N A$. The nucleotide sequence of the coding region of the LDL receptor gene in the 2 index patients was determined by automated sequencing of amplified fragments of lymphoblastoid cell mRNA amplified by RT-PCR. Regions of the LDL receptor gene encompassing exons or pairs of exons and the promoter were also amplified from genomic DNA, and their nucleotide

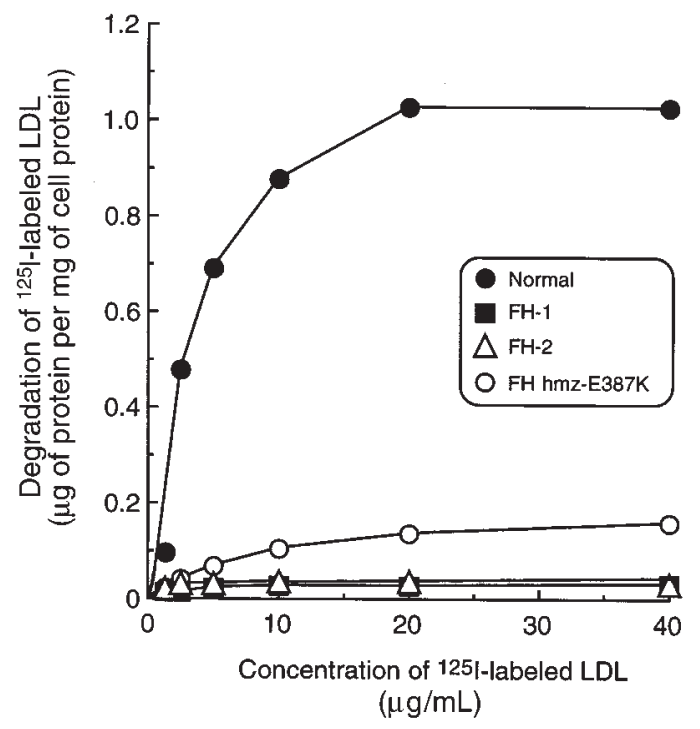

Figure 3

Degradation of ${ }^{125}$ I-labeled LDL by cultured lymphoblasts. Lymphoblasts from the index patients, a known homozygous $\mathrm{FH}$ patient, and a normolipemic control were preincubated in medium containing lipoprotein-deficient serum and compactin for 18 hours, and then for 4 hours at $37^{\circ} \mathrm{C}$ in the same medium containing different concentrations of ${ }^{125}$ I-labeled LDL (specific activity $=250 \mathrm{dpm} / \mathrm{mg}$ of protein). Values shown are for saturable degradation - that is, the difference in the amount of labeled LDL degraded in the presence or absence of excess unlabeled LDL $(1 \mathrm{mg} / \mathrm{mL})$ - and are the mean of triplicate incubations. $\mathrm{FH}-1$, the index patient in family $1 ; \mathrm{FH}-2$, the index patient in family 2; FH-hmz-E387K, patient known to be homozygous for the E387K mutation in the LDL receptor gene. sequence was determined. No differences were observed between the sequence in the patients and the sequence obtained with DNA or mRNA from normolipemic individuals. The index patient in family 1 was heterozygous at a number of bi-allelic polymorphic sites in the gene, including HincII in exon 12 (16), Avall in exon 13 (17), BsmAI in exon 10 (18), and HhaI in intron 9 (19); the polymorphisms that are present in the coding region were clearly detectable in the mRNA (data not shown), confirming that mRNA was expressed from both alleles. The index patient in family 2 was homozygous at all polymorphic sites examined.

Further evidence that the genetic defect in the two families was not in the LDL receptor gene itself was obtained from analysis of polymorphic microsatellite markers D19S394 and D19S221, which flank the LDL receptor gene (Figure 1). Both parents (I,3 and I,4) of the index patient in family 1 were heterozygous for different alleles at the LDL receptor locus; the father $(\mathrm{I}, 5)$ of the affected cousin (II,7) was also heterozygous, but shared 1 allele with his cousin, who was the father of the index patient $(I, 3)$. There was no indication of recombination in any of the affected offspring, although there was a single recombination event between the two markers in 1 unaffected individual (II,4). Although two of the affected individuals in 1 branch of this family (II,1 and II,5) inherited the same two alleles of the LDL receptor gene from their parents, one unaffected sibling (II,6) also inherited these same two alleles, and the third affected individual (II,7) inherited two completely different alleles. The parents in family 2 were both heterozygous for both markers, but had one allele in common; the affected siblings in family 2 each inherited different alleles of the LDL receptor gene from their parents.

Analysis of the apo $B$ gene. None of the known mutations in the gene for apo B were detected in genomic DNA from the index patients, and no one allele of the microsatellite marker D2S131, which is closely linked to the gene for apo B (GENATLAS linkage database), cosegregated with the severe hypercholesterolemia in both families (E. Eden et al., unpublished data).

Analysis of the $L D L$ receptor protein. Expression of the LDL receptor protein in cells was analyzed by immunoblotting of extracts of EBV-transformed lymphoblasts from the two index patients, normolipemic controls, and $\mathrm{FH}$ patients with known mutations in the LDL receptor gene. Cells from both patients contained a band that was detected by specific antibodies to the LDL receptor, with the same electrophoretic mobility and at least the same intensity as that in cells from normolipemic individuals, with no evidence of accumulation of any other forms of the protein (Figure 2a). Expression of the protein was induced in cells incubated in lipoprotein-deficient medium containing compactin and repressed when sterols were included in the medium. The LDL receptor protein on blots bound ${ }^{125} \mathrm{I}$-labeled lipoproteins apparently normally, com- 


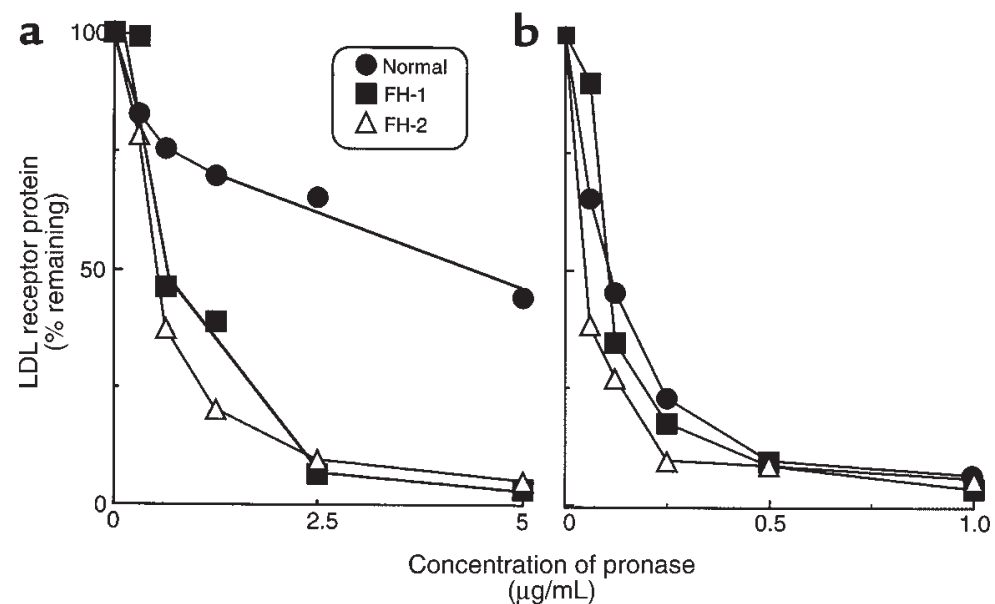

\section{Figure 4}

Effect of incubation with pronase on LDL receptor protein content of cultured lymphoblasts. Cultured lymphoblasts from the index patients and a normolipemic control were preincubated in medium containing lipoprotein-deficient serum and compactin for 18 hours, and then washed and incubated in serum-free medium for 30 minutes at either $4^{\circ} \mathrm{C}$ (a) or $37^{\circ} \mathrm{C}$ (b) with different concentrations of pronase. The digestion was terminated by the addition of serum ( $10 \% \mathrm{vol} / \mathrm{vol})$, and the relative amount of $L D L$ receptor protein remaining in the cells was determined by densitometry of the bands following immunoblotting of cell extracts. The results are expressed as a percentage of the amount of receptor protein in untreated cells, and are the mean of triplicate incubations. pared with that from patients who were either heterozygous or homozygous for known mutations in the LDL receptor gene (Figure $2 b$ ).

Analysis of LDL receptor function. Despite the presence of apparently normal LDL receptor protein in the cells of the two index patients, neither cell line was able to degrade ${ }^{125}$ I-labeled LDL (Figure 3). This suggested that the receptor protein might not be on the cell surface or that the receptor was unable to bind LDL. To investigate this, intact cells were incubated with pronase and then analyzed by immunoblotting of cell extracts with specific anti-LDL receptor antibodies. As shown in Figure 4, when normal cells were incubated at $4^{\circ} \mathrm{C}$, approximately $60 \%$ of the protein was accessible to degradation by pronase, whereas all the LDL receptor protein was accessible in cells from the two index patients. When the incubation was carried out at $37^{\circ} \mathrm{C}$, all the LDL receptor protein in all cell types was accessible to pronase. These results imply that all the receptor protein in the cells from the patient is located on the cell surface, unlike the situation in normal cells, where part of the protein is intracellular because it is constantly being internalized.

Measurement of LDL receptor binding of ${ }^{125} \mathrm{I}$-labeled lipoproteins by the nonadherent lymphoblasts poses technical problems caused by losses during the washing procedure, resulting in lack of reproducibility and unacceptably high levels of nonsaturable binding of radioactivity. Therefore, binding of fluorescently labeled LDL to the receptor protein in intact cells was determined by FACS analysis. Cells were incubated with BODIPY-labeled LDL at $4{ }^{\circ} \mathrm{C}$ in the presence or absence of excess unlabeled LDL (Figure 5). Cells from both index patients bound at least as much LDL as cells from normolipemic individuals, whereas cells from the FH patient homozygous for the Glu387Lys mutation (Figure 3 ) in the LDL receptor gene exhibited no saturable binding. Cells from normolipemic individuals or the index patients exhibited undetectable saturable binding when preincubated in medium containing sterols (data not shown).

To determine whether the LDL receptor protein could be internalized, cells were incubated with a chick- en polyclonal antibody to the LDL receptor at $4{ }^{\circ} \mathrm{C}$ for 30 minutes, washed extensively, and then incubated at $37^{\circ} \mathrm{C}$ for 30 minutes or maintained at $4^{\circ} \mathrm{C}$. Bound antibody that remained on the cell surface was detected with fluorescence-labeled goat anti-chicken IgG. The results showed that after incubation with the anti-LDL receptor antibody at $4{ }^{\circ} \mathrm{C}$, anti-LDL receptor antibody was detectable on the surface of cells from both a normolipemic individual and from the two index patients (Figure 6). Cells preincubated in medium containing sterols bound undetectable amounts of the antibody (data not shown). After incubation of the antibody-labeled cells at $37^{\circ} \mathrm{C}$, the fluorescence intensity of the cells from normolipemic individuals was reduced to that of unlabeled cells, showing that all the receptor-bound antibody had been internalized. When the incubation at $37^{\circ} \mathrm{C}$ was carried out in the presence of NEM, which inhibits internalization of LDL receptors (20), all of the anti-LDL receptor antibody remained on the cell surface. The fluorescence intensity of the antibody-labeled cells from the index patients remained unchanged when they were incubated at $37^{\circ} \mathrm{C}$ in the presence or absence of NEM, showing that all of the antibody remained on the cell surface. These results showed that the cells from the two patients were unable to internalize LDL receptors at $37^{\circ} \mathrm{C}$.

Measurement of receptor-mediated uptake of transferrin. The results suggested that the cells produced a normal LDL receptor protein that reached the cell surface and was able to bind LDL with high affinity, but was not internalized. To investigate whether this was due to some general defect in receptor-mediated endocytosis in the cells, binding and internalization of ${ }^{125} \mathrm{I}$-labeled transferrin by the transferrin receptor were determined. Cells were incubated at $4^{\circ} \mathrm{C}$ with labeled transferrin, washed, then incubated at $37^{\circ} \mathrm{C}$. At the time points shown (Figure 7), cells were analyzed for the amount of transferrin that was surface bound, internalized, or released into the medium. Cells from the two patients were able to internalize and recycle transferrin at the same rate as cells from normolipemic controls and a receptor-negative homozygous $\mathrm{FH}$ patient, suggesting 
that the cellular machinery for internalization of the transferrin receptor was intact.

\section{Discussion}

In this paper, we have described two unrelated individuals who fulfill most of the criteria for a diagnosis of homozygous $\mathrm{FH}$, but who do not have a detectable defect in the LDL receptor gene. Their two families are of different ethnic origin and are unlikely to share a common ancestor, but the biochemical defect in cultured cells and what is known of the pattern of inheritance share many features in the affected individuals. Both index patients have a similarly affected sibling, but all four parents are normolipemic or only mildly hypercholesterolemic, suggesting that the defect in the offspring is inherited as an autosomal recessive trait. This is supported by the observation that the affected individuals are offspring of consanguineous parents. Analysis of polymorphic markers in both families confirmed that the disorder does not cosegregate with an allele of either the LDL receptor or apo B genes. Both patients are heterozygous at the LDL receptor locus, and in one patient this has enabled us to confirm that mRNA from both alleles is present in the cells in approximately equal proportions. This precludes the presence of some mutation in noncoding regions of the LDL receptor gene that affects mRNA expression but cannot be detected with current technology and information. In particular, no mutations could be observed in the region coding for the cytoplasmic tail of the protein.

Immunoblotting of cell extracts with specific antibodies to the LDL receptor revealed the presence of a protein of normal mobility and showed that expression of the protein was regulated apparently normally by sterols. Unlike the situation in normal cells, where about half the LDL receptor protein is inside the cell at any time because it is constantly being internalized and recycled to the cell membrane (12), essentially all of the protein in the cells from these patients was located on the cell surface, implying that newly synthesized receptor was transported normally to the cell membrane and remained there. Because the receptor was also able to bind LDL apparently normally, these investigations suggested that internalization or intracellular trafficking of the LDL receptor is defective. This was supported by FACS analysis of the binding and uptake of an anti-LDL receptor antibody by the cells.

The observation that the patients are otherwise healthy, apart from the heart problems associated with hypercholesterolemia, implies that the defect cannot be a general defect in receptor-mediated endocytosis and is presumably specific for the LDL receptor; we have confirmed that internalization of transferrin by the transferrin receptor occurs normally. Internalization of many cell-surface receptors, including the LDL receptor and the transferrin receptor, occurs by clustering of receptor-ligand complexes in specialized areas of the cell surface known as clathrin-coated pits, followed by invagination of the coated pits to form intracellular

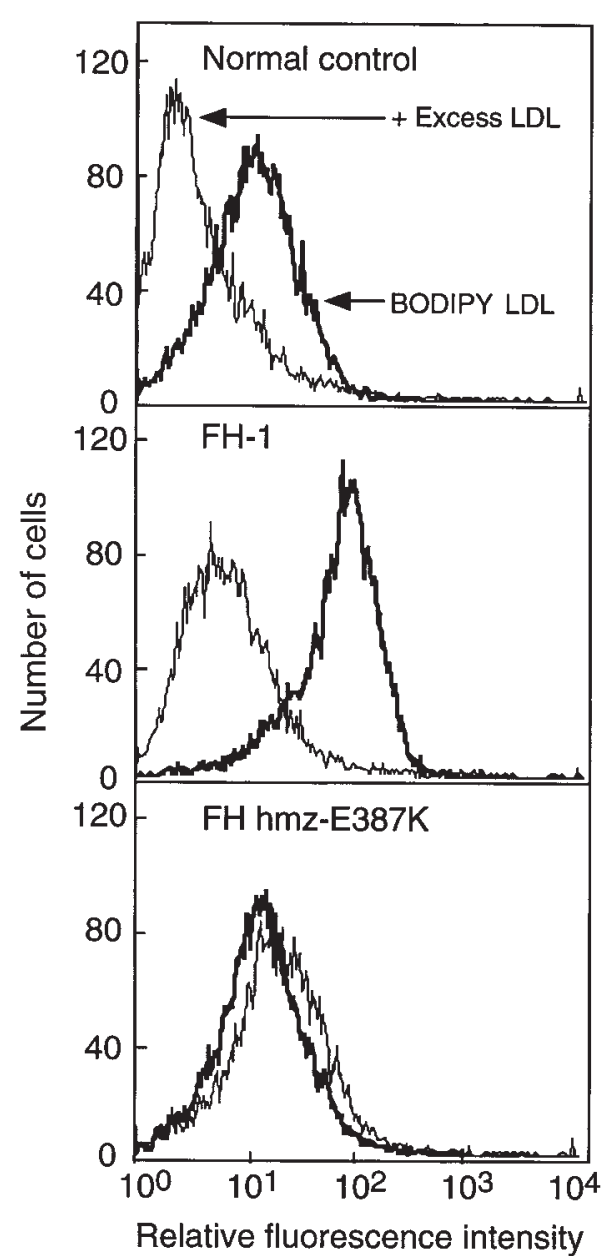

Figure 5

FACS analysis of binding of LDL to cultured lymphoblasts. Lymphoblasts from $\mathrm{FH}$ patients and a normolipemic control were preincubated in medium containing lipoprotein-deficient serum and compactin for 18 hours, and then with BODIPY-FL LDL complex $(20 \mu \mathrm{g}$ $\mathrm{LDL}$ protein $/ \mathrm{mL}$ ) at $4{ }^{\circ} \mathrm{C}$ for 30 minutes in the presence or absence of an excess $(1 \mathrm{mg} / \mathrm{mL})$ of unlabeled human LDL. Cells were washed and fixed in $2 \%$ paraformaldehyde for FACS analysis as described in Methods. $\mathrm{FH}-1$, index patient in family 1 ; normal control, normolipemic subject; FH hmz-E387K, patient homozygous for E387K.

endosomes that eventually fuse with lysosomes, where dissociation of the receptor and ligand occurs (21). Although it was first thought that receptors compete for a common mechanism of uptake through coated pits (21), implying a common uptake mechanism, more recent studies have shown that the LDL receptor does not compete with either the transferrin receptor or the EGF receptor for uptake, at least in heterologous cells overexpressing one or the other receptor $(22,23)$, and that there are distinct saturable pathways for uptake of receptors with dileucine- and tyrosine-based sorting signals (24). Thus, it is likely that some component of the uptake mechanism is specific for different receptors and that the genetic defect in our patients occurs here.

Uptake of cell-surface receptors through clathrincoated pits is thought to occur by initial interaction of a protein motif in the cytoplasmic domain of the recep- 


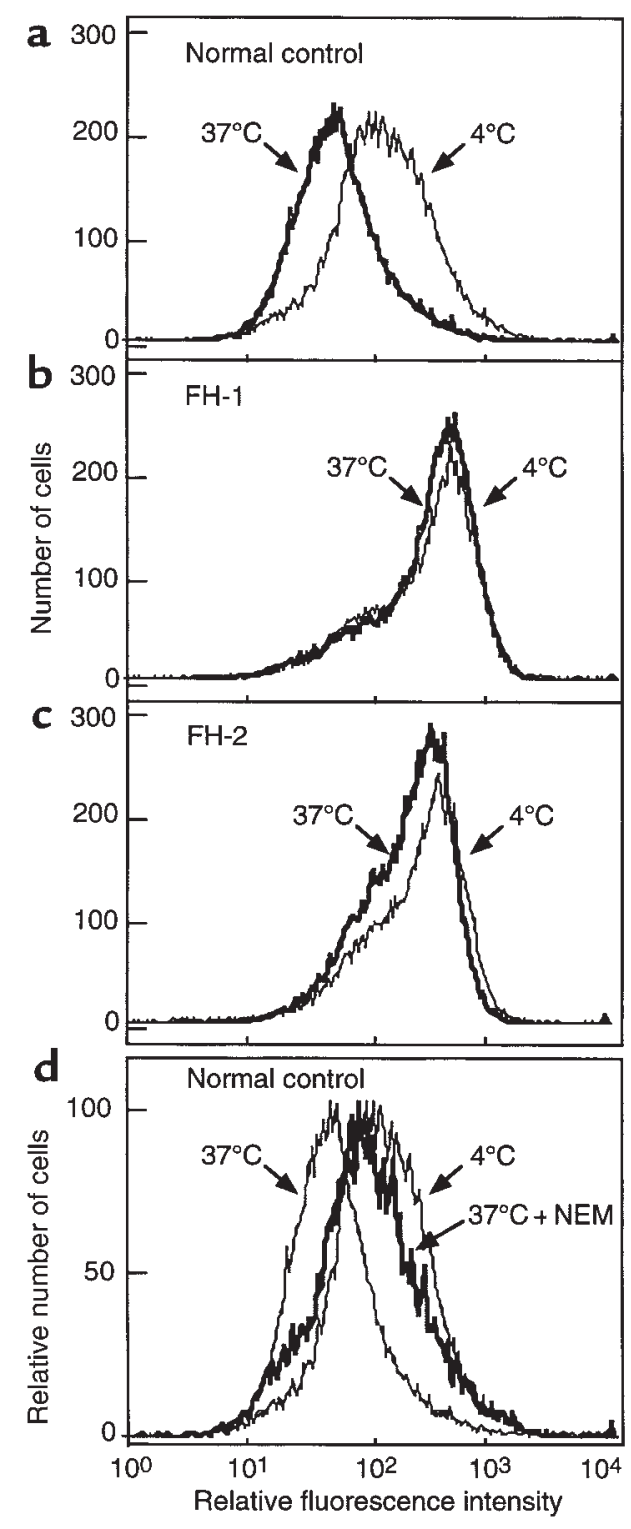

Figure 6

FACS analysis of internalization of LDL receptor protein to cultured lymphoblasts. Lymphoblasts from the index patients and a normolipemic control were preincubated in medium containing lipoprotein-deficient serum and compactin for 18 hours, and then with a chicken anti-LDL receptor IgG at $4^{\circ} \mathrm{C}$ for 60 minutes. Cells were washed, and then either maintained at $4^{\circ} \mathrm{C}$ or incubated at $37^{\circ} \mathrm{C}$ for 30 minutes $(\mathbf{a}, \mathbf{b}$, and $\mathbf{c})$ in the presence or absence of $2 \mathrm{mM} \mathrm{N}$-ethyl maleimide (d), which inhibits internalization of LDL receptors by normal cells (20). After the incubations, the cells were chilled and incubated with Alexa-488 goat anti-chicken $\operatorname{lgG}(\mathrm{H}+\mathrm{L})$ conjugate for 15 minutes at $4^{\circ} \mathrm{C}$, and then washed and fixed in $2 \%$ paraformaldehyde for FACS analysis as described in Methods. ( $a$ and $\mathbf{d}$ ) Cells from a normolipemic control; (b) cells from $\mathrm{FH}-1$, the index patient in family $1 ;$ (c) cells from $\mathrm{FH}-2$, the index patient in family 2 .

tor known as the internalization signal with adaptor protein (AP) complexes that are associated with clathrin (25). AP complexes comprise 4 different polypeptide subunits - two large ( $\beta$-adaptin and either $\alpha$-adaptin or $\gamma$-adaptin), one medium $(\mu)$, and one small $(\sigma)$. It has been found that the $\beta$-adaptin subunit in AP-2 promotes assembly of the clathrin cage, while the $\mu 2$ subunit can interact with the YxxØ-type of internalization signal present in the cytoplasmic tail of some cell-surface receptors, including the transferrin receptor, where $\varnothing$ represents a bulky hydrophobic residue (reviewed in ref. 25). The internalization motif of the LDL receptor also involves a tyrosine residue, but comprises the 4-amino acid residue motif NPVY (26), which is also present in all other members of the gene family. Interaction of these signals with $\mu 2$ does not appear to have been investigated, and, indeed, a recent paper has suggested that the LDL receptor cytoplasmic tail may interact directly with part of the clathrin molecule without a requirement for an adaptor protein, at least in vitro (27). We have found that the nucleotide sequence of $\mu 2$ cDNA amplified from the cells of our two index patients is not significantly different from the published sequence for human $\mu 2$ (GENBANK HSU33188), although it does contain a number of silent polymorphisms and a splice variant that has been observed in murine $\mu 2$ (28), confirming that this is unlikely to be the defective gene (M. Bourbon et al., unpublished observations).

There is little doubt that there is a recessive gene defect in these two families that results in raised plasma cholesterol concentration, but we are aware that we have not yet proved that the defect in the patient's lymphoblasts is the underlying cause of this. For example, we have considered the possibility that the defect in the EBV-transformed lymphoblasts from these two patients is a feature of the particular cell type and might not be manifest in other tissues in vivo. This uncertainty will be impossible to resolve until we have identified the gene concerned. It is also possible that the cell types transformed from these two patients are defective in endocytosis of LDL receptors for some reason other than the nature of the genetic defect in these families. However, we have now transformed cell lines from more than 50 patients with a diagnosis of probable heterozygous FH and have never observed this particular biochemical defect in any of them, nor in approximately 10 normal control cell lines obtained from unaffected spouses. In any event, these cells with a defect in the internalization of $L D L$ receptors provide a unique tool for exploring this rather poorly defined cellular process.

There have been previous reports of patients with a diagnosis of homozygous $\mathrm{FH}$ who do not appear to have a defect in LDL receptor function in cultured cells or in the sequence of the gene. Cases of pseudohomozygous FH were described some years ago, but these were probably due to sitosterolemia (1). In the index patient in family 1 , sitosterolemia was excluded by measuring plasma plant sterol levels (29). It is also worth mentioning in this context that this patient (FH1) showed unusually good response to treatment with atorvastatin (80 mg at night) and cholestyramine (16 $\mathrm{g} / \mathrm{d}$ ), and her current total plasma cholesterol is in the range $6.0-7.5 \mathrm{mmol} / \mathrm{L}$. However, treatment with 


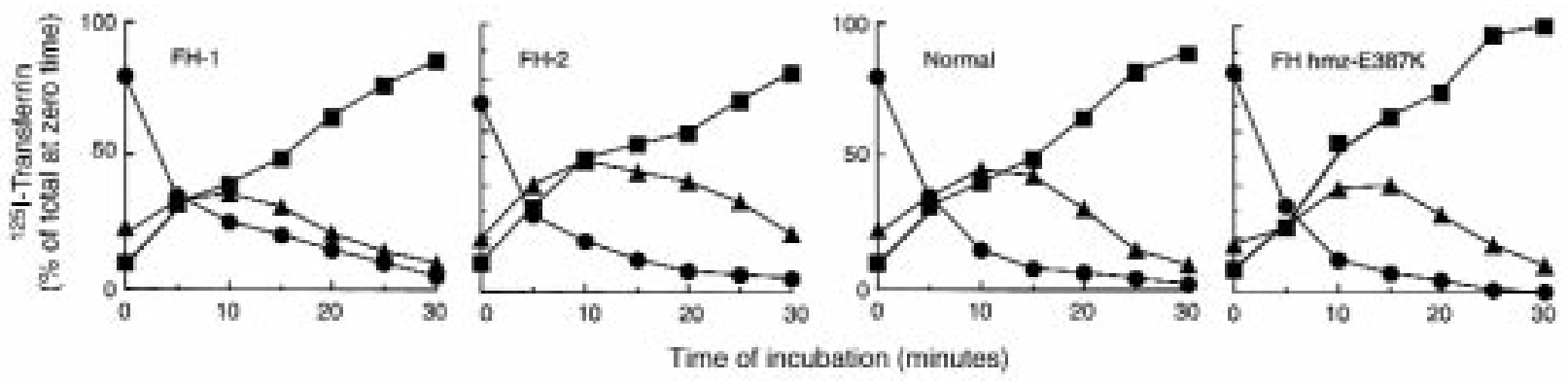

Figure 7

Time course of internalization of transferrin by cultured lymphoblasts. Cultured lymphoblasts $\left(0.5 \times 10^{7}\right.$ cells $\left./ \mathrm{mL}\right)$ were incubated at $4^{\circ} \mathrm{C}$ for 60 minutes in RPMI-1640 medium containing ${ }^{125}$-labeled transferrin $(0.2 \mu \mathrm{g} / \mathrm{mL}$, specific activity $=1,198 \mathrm{dpm} / \mathrm{ng}$ of protein $)$. Excess unlabeled transferrin was then added $(10 \mu \mathrm{g} / \mathrm{mL})$, and the cells were incubated for the indicated times at $37^{\circ} \mathrm{C}$. At each time point, the medium was removed, and the cells were washed with $0.2 \mathrm{M}$ acetic acid, $0.5 \mathrm{M} \mathrm{NaCl}(\mathrm{pH} 2.4)$ to remove surface-bound transferrin and then were solubilized in $1 \mathrm{M} \mathrm{NaOH}$ (15). Radioactivity in the medium (transferrin released into the medium), acid wash (surface-bound transferrin), and solubilized cells (internalized transferrin) was determined and expressed as a percentage of the total radioactivity at zero time. Values shown are means of triplicate incubations. At zero time, the total amount of labeled transferrin associated with the cells (ng of transferrin per mg of cell protein) was as follows: FH-1, 41.2; FH-2, 18.6; FH hmz-E387K, 32.3; normal control, 19.3.

cholestyramine alone for a short period led to a marked increase in her cholesterol level, to $11.3 \mathrm{mmol} / \mathrm{L}$. A good response to treatment with lipid-lowering therapy might be interpreted to show that LDL receptor function must be intact, but we have shown previously that a homozygous FH patient with a null LDL receptor phenotype caused by a premature stop codon in the LDL receptor gene responded well to treatment with statins (30). More recently, an Italian family has been described in which homozygous FH did not cosegregate with alleles of the LDL receptor gene or the gene for apo B, and sitosterolemia was excluded (31). A single severely hypercholesterolemic individual of Turkish origin has also been described in whom LDL clearance from plasma was delayed, but the LDL receptor was apparently normal (32). However, the LDLbinding data reported in that study are difficult to interpret, and there was no direct evidence that the defect was inherited because the affected individual was a member of a large family, none of whom were even mildly hypercholesterolemic (32). More convincing evidence that inherited defects in genes other than those for the LDL receptor and apo B can cause the hypercholesterolemia typical of $\mathrm{FH}$ has come from analysis of the gene defect in large cohorts of patients with a diagnosis of heterozygous FH. In several of these cohorts, exhaustive analysis of the LDL receptor gene has failed to reveal a defect in about $15 \%$ of the patients, and in 2 such studies a family with a sufficiently large pedigree was available to determine that an allele of these genes did not cosegregate with hypercholesterolemia, suggesting that their genetic defect also lay elsewhere (3, 33). These observations suggest that a hitherto unknown defect (or defects) might be a fairly frequent cause of the FH phenotype, and that identification of these would be of value for screening of affected relatives and might suggest a more appropriate method of treatment than those currently in use for $\mathrm{FH}$ patients with known genetic defects.

\section{Acknowledgments}

Bruce Pottinger provided assistance with tissue culture, and Emily Eden carried out some of the genotyping. Part of this work was supported by the British Heart Foundation (project grants PG 93005 and PG 98062). A.K. Soutar and R. Naoumova are grateful to the British Hyperlipidaemia Association for a Sue McCarthy Travel Grant to enable collection of samples from relatives in family 1 , and to the family for their willing cooperation.

1. Goldstein, J.L., Hobbs, H., and Brown, M.S. 1995. Familial hypercholesterolemia. In The Metabolic and molecular bases of inherited disease. C.R. Scriver et al., editors. McGraw-Hill. New York, NY. 1981-2030.

2. Sun, X.M., Patel, D.D., Knight, B.L., and Soutar, A.K. 1998. Influence of genotype at the low density lipoprotein (LDL) receptor gene locus on the clinical phenotype and response to lipid-lowering drug therapy in heterozygous familial hypercholesterolemia. The Familial Hypercholesterolaemia Regression Study Group. Atherosclerosis. 136:175-185.

3. Sun, X.M., Patel, D.D., Knight, B.L., and Soutar, A.K. 1997. Comparison of the genetic defect with LDL-receptor activity in cultured cells from patients with a clinical diagnosis of heterozygous familial hypercholesterolemia. Arterioscler. Thromb. Vasc. Biol. 17:3092-3101.

4. Pimstone, S.N., et al. 1998. Phenotypic variation in heterozygous familial hypercholesterolemia: a comparison of Chinese patients with the same or similar mutations in the LDL receptor gene in China or Canada. Arterioscler. Thromb. Vasc. Biol. 18:309-315.

5. Day, I., et al. 1997. Spectrum of LDL receptor gene mutations in heterozygous familial hypercholesterolemia. Hum. Mutat. 10:116-127.

6. Rallidis, L., Nihoyannopoulos, P., and Thompson, G.R. 1996. Aortic stenosis in homozygous familial hypercholesterolaemia. Heart. 76:84-85.

7. Sun, X.M., Patel, D.D., Bhatnagar, D., Knight, B.L., and Soutar, A.K. 1995. Characterization of a splice-site mutation in the gene for the LDL receptor associated with an unpredictably severe clinical phenotype in English patients with heterozygous FH. Arterioscler. Thromb. Vasc. Biol. 15:219-227.

8. Soutar, A.K., Knight, B.L., and Patel, D.D. 1989. Identification of a point mutation in growth factor repeat $\mathrm{C}$ of the low density lipoprotein-receptor gene in a patient with homozygous familial hypercholesterolemia that affects ligand binding and intracellular movement of receptors. Proc. Natl. Acad. Sci. USA.. 86:4166-4170.

9. Webb, J.C., et al. 1992. Characterization of two new point mutations in the low density lipoprotein receptor genes of an English patient with homozygous familial hypercholesterolemia. J. Lipid. Res. 33:689-698.

10. Sun, X.M., et al. 1992. Characterization of deletions in the LDL receptor gene in patients with familial hypercholesterolemia in the United Kingdom. Arterioscler. Thromb. 12:762-770.

11. Day, I., et al. 1997. Identification of a common low density lipoprotein receptor mutation $(\mathrm{r} 329 \mathrm{x})$ in the south of England: complete linkage disequilibrium with an allele of microsatellite d19s394. J. Med. Genet. 34:111-116. 
12. Knight, B.L., Gavigan, S.J., Soutar, A.K., and Patel, D.D. 1989. Defective processing and binding of low-density lipoprotein receptors in fibroblasts from a familial hypercholesterolaemic subject. Eur. J. Biochem. 179:693-698.

13. Soutar, A.K., and Knight, B.L. 1986. Immunoprecipitation of the lowdensity-lipoprotein (LDL) receptor and its precursor from human monocyte-derived macrophages. Biochem. J. 233:683-690.

14. Buchegger, F., Trowbridge, I.S., Liu, L.F., White, S., and Collawn, J.F. 1996. Functional analysis of human/chicken transferrin receptor chimeras indicates that the carboxy-terminal region is important for ligand binding. Eur. J. Biochem. 235:9-17.

15. Hopkins, C.R., and Trowbridge, I.S. 1983. Internalization and processing of transferrin and the transferrin receptor in human carcinoma A431 cells. J. Cell Biol. 97:508-521.

16. Leitersdorf, E., and Hobbs, H.H. 1988. Human LDL receptor gene: HincII polymorphism detected by gene amplification. Nucleic Acids Res. 16:7215.

17. Hobbs, H.H., Esser, V., and Russell, D.W. 1987. AvaII polymorphism in the human LDL receptor gene. Nucleic Acids Res. 15:379.

18. Warnich, L., Kotze, M.J., Langenhoven, E., and Retief, A.E. 1992. Detection of a frequent polymorphism in exon 10 of the low-density lipoprotein receptor gene. Hum. Genet. 89:362.

19. Webb, J.C., Patel, D.D., Shoulders, C.C., Knight, B.L., and Soutar, A.K. 1996. Genetic variation at a splicing branch point in intron 9 of the low density lipoprotein (LDL)-receptor gene: a rare mutation that disrupts mRNA splicing in a patient with familial hypercholesterolaemia and a common polymorphism. Hum. Mol. Genet. 5:1325-1331.

20. Brown, M.S., and Goldstein, J.L. 1976. Analysis of a mutant strain of human fibroblasts with a defect in the internalization of receptor-bound low density lipoprotein. Cell. 9:663-674.

21. Pearse, B.M., and Robinson, M.S. 1990. Clathrin, adaptors, and sorting. Annu. Rev. Cell. Biol. 6:151-171.

22. Warren, R.A., Green, F.A., and Enns, C.A. 1997. Saturation of the endocytic pathway for the transferrin receptor does not affect the endocytosis of the epidermal growth factor receptor. J. Biol. Chem. 272:2116-2121.

23. Warren, R.A., Green, F.A., Stenberg, P.E., and Enns, C.A. 1998. Distinct saturable pathways for the endocytosis of different tyrosine motifs. $J$.
Biol. Chem. 273:17056-17063.

24. Marks, M.S., Woodruff, L., Ohno, H., and Bonifacino, J.S. 1996. Protein targeting by tyrosine- and di-leucine-based signals: evidence for distinct saturable components. J. Cell Biol. 135:341-354.

25. Robinson, M.S. 1994. The role of clathrin, adaptors and dynamin in endocytosis. Curr. Opin. Cell Biol. 6:538-544.

26. Davis, C.G., van Driel, I.R., Russell, D.W., Brown, M.S., and Goldstein, J.L. 1987. The low density lipoprotein receptor. Identification of amino acids in cytoplasmic domain required for rapid endocytosis. J. Biol. Chem. 262:4075-4082.

27. Kibbey, R.G., Rizo, J., Gierasch, L.M., and Anderson, R.G. 1998. The LDL receptor clustering motif interacts with the clathrin terminal domain in a reverse turn conformation. J. Cell Biol. 142:59-67.

28. Ohno, H., Poy, G., and Bonifacino, J.S. 1998. Cloning of the gene encoding the murine clathrin-associated adaptor medium chain mu 2: gene organization, alternative splicing and chromosomal assignment. Gene. 210:187-193.

29. Wolthers, B.G., et al. 1991. Use of determinations of 7-lathosterol (5 alpha-cholest-7-en-3 beta-ol) and other cholesterol precursors in serum in the study and treatment of disturbances of sterol metabolism, particularly cerebrotendinous xanthomatosis. J. Lipid. Res. 32:603-612.

30. Zuliani, G., et al. 1995. Severe hypercholesterolaemia: unusual inheritance in an Italian pedigree. Eur. J. Clin. Invest. 25:322-331.

31. Feher, M.D., et al. 1993. Cholesterol-lowering drug therapy in a patient with receptor-negative homozygous familial hypercholesterolaemia Atherosclerosis. 103:171-180

32. Schmidt, H.H., et al. 1998. Delayed low density lipoprotein (LDL) catabolism despite a functional intact LDL-apolipoprotein B particle and LDL-receptor in a subject with clinical homozygous familial hypercholesterolemia. J. Clin. Endocrinol. Metab. 83:2167-2174.

33. Haddad, L., et al. 1999. Evidence for a third genetic locus causing familial hypercholesterolemia. A non-LDLR, non-APOB kindred. J. Lipid Res. 40:1113-1122.

34. Webb, J.C., et al. 1996. Characterization of mutations in the low density lipoprotein (LDL)-receptor gene in patients with homozygous familial hypercholesterolemia, and frequency of these mutations in $\mathrm{FH}$ patients in the United Kingdom. J. Lipid. Res. 37:368-381. 